\title{
Cohort profile: study of practical undergraduate education in Germany
}

\author{
Richard Kasch ${ }^{1 *}$, Laura Klene ${ }^{1}$, Arndt Peter Schulz ${ }^{2}$, Michael Förch ${ }^{3}$, Adrian Meder ${ }^{4}$, Mattias Abert ${ }^{1}$, Eva Abert ${ }^{1}$ and Susanne Fröhlich ${ }^{5}$
}

${ }^{1}$ Department of Orthopedics and Orthopedic Surgery, University Medicine Greifswald, Germany

${ }^{2}$ Department of Orthopedic and Trauma Surgery, University Hospital Schleswig-Holstein, Campus Lübeck, Germany

${ }^{3}$ Faculty of Key Competencies, University of Applied Management, Erding, Germany

${ }^{4}$ Department of Trauma Surgery, Traumahospital Tübingen, Germany

${ }^{5}$ Department of Orthopedics and Orthopedic Surgery, University of Rostock, Germany

\begin{abstract}
Introduction: Expecting a significant lack of medical doctors in a few years, there has been growing concern how to attract young doctors to work in hospitals and private practices in areas of shortage. To address workforce shortages, we need more detailed information about medical students' and young doctors' expectations and the factors discouraging them from choosing certain careers. To obtain this information, a national brain trust developed a cross-sectional

questionnaire focusing on the internships. In this publication we introduce the study as well as the internet-based online data collecting process as a basis the presentation of our subsequent data analyses, which will be performed for different research topics and subgroups.

Material and Methods: A national brain trust designed an online-based survey with a minimum of 153 questions per participant. The questionnaire was open for participant input nationwide from Friday, 13th of 15 April 2012 until Monday, 24th of September 2012. A total of 9,079 medical students and junior residents finally answered the questionnaire.

Results: The results from our pilot study show that the questionnaire is actually measuring motivational and frustrating factors of future German doctors. Participants on average answered this survey within 1.05 days; however, there was a very wide range. Most questionnaires were completed on Fridays. We did not identify relevant associations between higher e-learning affinity, more intense computer uses or the size of university and faster submission of questionnaires. There also were no gender differences. Further analyses of the survey data will be performed to learn more about motivational and frustrating factors.
\end{abstract}

Discussion: Central parameters of the results are comparable to other studies. We are confident that the questionnaire has enough statistical power to answer the questions that were addressed and that must be answered to prevent a severe lack of medical practitioners in a few years.

\section{Introduction}

An increasing shortage and unequal distribution of physicians are a reality around the world. A lack of doctors has been described in reports from Australia [1], Canada [2], Germany [3-8] and the USA $[9,10]$ for more than 50 years. In all countries, the problems first started in rural areas. So, not only in Germany, there has been growing concern as to how adequate health care can be provided in the future. Kopetsch, et al. reported that, in Germany, the proportion of doctors younger than 35 dropped from $26.6 \%$ in 1993 to $16.6 \%$ in 2006 . Reasons for this development include that about $18 \%$ of all medical students drop out and that another $11.6 \%$ seek positions outside patient care. Overall, there is a net loss of one third of all study beginners in Germany $[6,11]$.

Also contributing to this negative trend is what has been described as "generation Y". Generation Y consists of young workplace entrants born after 1981 [12-14]. Hospitals wishing to employ this new generation of physicians must be prepared to respond to their expectations [15]. Schmidt identified five factors that are important to generation $\mathrm{Y}$ job seekers. Achieving their desired work-life balance seems to be their first priority. Unlike former generations of young doctors, they want to enjoy spare time and family life. Another point is that they expect to continue being trained while on the job. They want career development through additional training, for example mentoring programs are wellrated. Growing evidence suggests that multiple-method approaches in training are preferred, while online learning receives poor ratings [16]. These results concerning preferred training methods are confirmed by Birch and colleagues [17], while other groups report different findings $[12,15,18,19,20]$.

Different national and international studies were performed to investigate medical students' satisfaction with study conditions and to elucidate their expectations regarding their professional future and workplace in health care with a view to using these insights to

${ }^{\star}$ Correspondence to: Richard Kasch, PhD, MD, MSc, Clinic for Orthopedics and Orthopedic Surgery Ernst Moritz Arndt University Greifswald FerdinandSauerbruch-Straße, D-17475 Greifswald, Germany, Tel: +49 383486 7061; E-mail: richard.kasch@uni-greifswald.de

Key words: undergraduate education, practical training, internship, online survey, standards, physician's role, psychology, medical students, sex factors, questionnaires, national study, Germany, mental-health problems, stress

Received: August 28, 2018; Accepted: September 04, 2018; Published: September 07, 2018 
attract young doctors to fields of employment with a growing shortage $[8,12,13,15,20-24]$. Other investigators tried to elucidate what young doctors expect of their employment, e.g., in terms of salary opportunities or secure employment $[8,21]$. Recently, Stagg and colleagues presented strong evidence that high-quality teachers during internship can motivate students to work in primary care environments $[23,25]$.

Along with the importance generation $\mathrm{Y}$ jobseekers attach to ongoing training on the job, the observation that internship in internships attractive and creating incentives at this stage of the career of physicians may be promising in attracting young doctors to work in hospitals and private practices in areas of shortage. Therefore, we need more detailed information about medical students' and young doctors' expectations and the factors discouraging them from choosing certain careers. To obtain this information, a national brain trust developed a cross-sectional questionnaire focusing on the internships that are part of the curriculum of medical students in Germany. The questionnaire has to major aims: to identify factors and circumstances of the work environment medical students experience leading to a positive curative approach and to elucidate the aspects students are most dissatisfied with. We expect that the results can help us in creating work environments that meet the needs of generation Y physicians, thereby attracting physicians to underserved areas.

Internet-based online surveys appear to be a useful tool to assess study-related factors such as the impact of different teaching methods. Such surveys have been widely used to assess the behavior or attitudes of students in general and also of medical students [26-29]. One study investigated students' reasons for not participating in surveys [29]. Students at an arts college were administered four different surveys throughout one academic year to examine how demographics, engagement, and Holland personality type affect cooperation. It was found that survey respondents were more likely to be female and socially engaged, less likely to be on financial aid, more likely to be an investigative personality type and less likely to be an enterprising personality type [29]. The lower response rate in web surveys has been a major concern for survey researchers, and one group systematically reviewed a wide variety of factors influencing the response rate in the stage of survey development, survey delivery, survey completion, and survey return [28]. For medical students, specific studies have investigated web affinity and online behavior such as online posting of unprofessional content by medical students [27] or Facebook use and the professional behaviors of undergraduate medical students [30]. The results of these studies suggest that medical students have a certain Internet affinity on a private and unprofessional level.

In this article, we describe our method and how we were able to motivate over 9,000 participants to complete and return a relatively complex and long online questionnaire of $>150$ to $>170$ questions per person $[31,32,29]$. We provide a detailed description of the questionnaire and the ideas behind each block of questions we included as well as of the survey procedure itself. Moreover, we outline results for special subgroups such as students differing in terms of computer use. Our intention in presenting our methodology in this paper is to lay the foundation for a series of analyses that are currently underway to answer different research questions. Furthermore, a detailed description of our methods as well as data on our experience with this approach, such as response rates or time to complete the questionnaire, might help others who are interested in doing similar research using an online questionnaire in other countries. In this way, we aim to better understand the population we survey and to make future surveys tailorable to specific target populations.

\section{Material and Method}

This study was approved by the Ethical Review Committee, University of Greifswald (72/2012). For our survey of medical students and young doctors in Germany, we developed an internet-based questionnaire. $[28,32]$ The survey was designed in three steps, using the software "EvaSys education" from electricpaper GmbH, Lüneburg, Germany. In a first pilot study conducted in 2011, medical students of three different universities were asked to complete the first version of the questionnaire to test the back office and the survey in general. A second pilot study was conducted in early 2012. Several inconsistencies were identified and modified. The nationwide online survey of German medical students and first-and second-year residents was started on Friday, 13th of April 2012 and ended on Monday, 24th of September 2012.

\section{Sampling design and data collection}

The study was designed to survey medical students as well as first- and second-year residents in Germany. In 2008, 76,042 medical students were enrolled at German universities. The number had been roughly constant over the five preceding years [6]. Additionally, young doctors at the beginning of their career were asked to complete the questionnaire. According to the German Federal Statistical Agency, there are no exact data on physicians in advanced training [6]. Based on older data, we expected approximately 10,000 residents as potential participants. Hence, the total potential target group of the survey was 90,000 participants. No sample selection was done.

The questionnaire is supposed to have explanatory power for the total population of medical students in Germany in the year under survey. Participation from individual universities may be too small to draw any conclusions regarding the situation at a specific university. Some of the parameters (e.g., students with children, students aiming for a scientific career or wanting to work in politics/industry) are expected to be underrepresented and will just give an impression.

The current questionnaire presented here provides the baseline data. Depending on the intra- and interindividual results, a follow-up survey will be conducted to find out whether any improvements have occurred concerning problems stated in the first survey. All participants were asked to consent to being contacted again.

\section{Structure of the questionnaire}

The questionnaire includes the following four main sections covering topics such as the importance of work-life balance, career opportunities, students' soft and hard skills, and training methods $[13,15]$. The number of questions in each section is given in Figure 1.

1) General questions concerning where, since when and until when students will be studying. They are also asked which specialty they think they will choose.

2) Reasons for studying medicine are elicited, e.g., family tradition, a strong wish to help others, or career opportunities. Furthermore, this part asks about the intended medical career in general terms, e.g., academic and research-related versus working with patients in a hospital or practice. Students/Interns who intend to work in a totally non- patient-related environment is asked to give reasons.

3) The largest section consists of questions for different addressees. Students in preclinical education receive questions concerning their practical training in patient care, students in clinical education receive questions concerning a clinical traineeship of $>4$ weeks duration, and students in and after their last year as well as graduates receive 


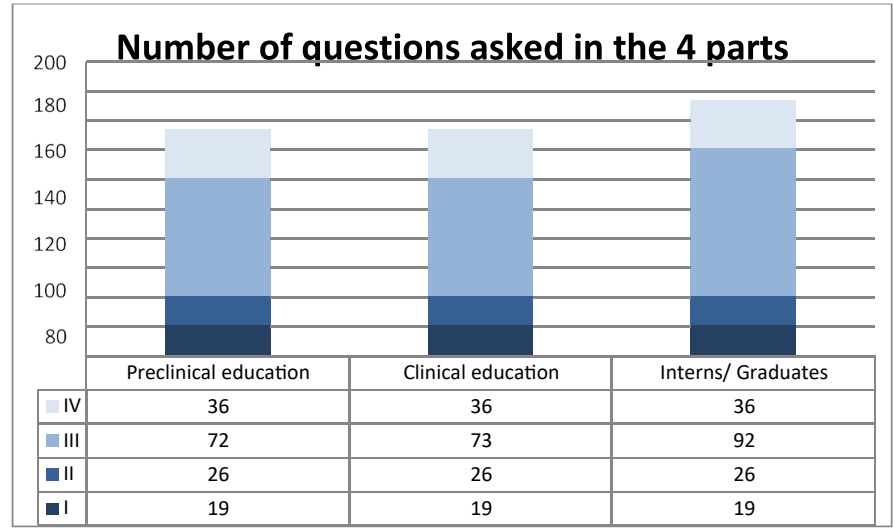

Figure 1. Number of questions asked in the different parts of the questionnaire

The bars represent the numbers of questions asked in the four main sections of the questionnaire for addresses at three stages of medical studies/training. The blue portions of the bars illustrate that the number only differs for section III of the questionnaire. The number of questions in this section ranges from 72 for preclinical students to 92 for interns and first-year residents.

questions concerning their internship. These questions pertain to general satisfaction with the practical experience and specific factors related to how practical training is imparted.

4) Social aspects such as gender, distance of university from home, family structure, and learning methods.

\section{Response and attrition}

The survey procedure consisted of two parts: first we advertised the survey at all universities and then sent out questionnaires to those students who registered to participate on our website.

After the pilot phase, we contacted medical students all over Germany using mailing lists of students' representatives from each university. Universities without such mailing lists were asked to advertise our survey via posters and flyers they were sent. Rates of responders substantially varied among universities and largely depended on whether a university supported our survey or not.

In the pilot studies, we mailed out reminders to non-responders to test the effectiveness of this measure $[28,29,26]$. During the actual survey, non-responders received up to four e- mails asking for return of completed questionnaires. Starting in week 24 , the first three e- mails were sent at weekly intervals to all non-responders, the final reminder one week before we closed the questionnaire. Universities with low application rates were contacted again and asked to remind their students to join our survey.

\section{Measurements and scaling}

The questionnaire includes mostly closed questions. Primary measurement scales are nominal or ordinal. For non-comparative scales, a five-point Likert scale was chosen. This number allows sufficient differentiation in statistical tests. Furthermore, research has shown that a five-point scale can be processed cognitively [33].

The "neutral" point in the middle of the scale is important as individuals indeed can have a neutral position [34]. A "captured in the middle" where students systematically choose this "neutral" point of the scale was not expected due to the high intrinsic motivation to answer the survey. Whenever an item had a high chance that the student might be unable to answer it, a category such as "no answer possible" was offered. Due to the fact that only the end-point of each item is verbalized, a five-point scale can be considered to be intervalscaled [35]. This is important for the statistical tests that can be used as a high level of measurement allows much more sophisticated statistical analysis than nominal or ordinal scales.

\section{Statistical analysis}

We tested normal distribution and variance homogeneity for metrically scaled variables (using Levene and Kolmogorov-Smirnov tests). Normally distributed data were analyzed with the $\mathrm{Chi}^{2}$ test and t-test, assuming statistically significant differences at p-values $<0.05$. Nonnormally distributed data were assessed using Spearman correlation, the Mann-Whitney U-test, or the Kruskal-Wallis test. For assessment of correlations (Pearson or Spearman), we followed the recommendations of Brosius (2011) [36]. All statistical tests were performed using SPSS v.21.

\section{Results \\ Pilot study}

The first and second pilot study was conducted in 175 and 218 students, respectively, approx. 53\% women and $47 \%$ men. The analysis of these data suggests that the reasons for choosing a medical career change significantly as students advance in their studies and gain practical experience. For more advanced students, work-life balance became a more important factor. Equally important were stability in employment and chances of advancement. Interest in research was constantly low. These results show that the questionnaire is actually measuring changes in motivational factors as students advance in their studies. Another important aim of the pilot phase was to test whether the questionnaire actually elucidates the factors that may influence motivation in a positive or negative way during the practical parts of medical education. Our preliminary analysis of the pilot phase suggests that, for example, integration into a team is considered a positive factor, as is participation in ward rounds. However, the latter is rarely possible. Based on these preliminary data, we are confident that the questionnaire will answer our questions and that the results can help in overcoming the increasing shortage of medical practitioners in Germany.

\section{Final questionnaire}

Response rates to the final questionnaire: During the survey period from Friday the 13th of April to Monday, 24th of September $2012,10,993$ individuals registered on our webpage to participate in the survey. Of these, 336 could not be sent the questionnaire because our mails were not delivered. Another 142 applied more than once but were contacted just once by e-mail. A total of 9079 individuals (of 10,993 people registered $=100 \%$ ) completed and returned the questionnaire. These data are represented graphically in Figure 2.

Time to complete the questionnaire: We analyzed the time elapsed between online registration and submission of the completed questionnaire. The mean interval was one day (mean 1.05; SD 17.69); however, there was a very wide range from immediate completion to a maximum delay of 164 days. The quartiles show that $25 \%$ of responders completed the questionnaire immediately after registration, $75 \%$ within 5 days.

We also analyzed whether faculty size had an effect on how long it took until completed questionnaires were submitted after registration. Based on the total number of all German medical students, we classified medical faculties as large when they were above the mean number of medical students and as small when they were below the 
mean. The t-test revealed no statistically significant difference in questionnaire submission time between students from large and small faculties $(\mathrm{p}=0.468)$. Moreover, we analyzed whether faculty size had an influence on which day of the week respondents returned the questionnaire. Students of larger faculties significantly more often completed questionnaires on Saturdays compared with students of smaller faculties ( $\mathrm{p}=0.018$; Figure 3 ).

There were marked differences among universities in how well our survey was supported and advertised or whether or not we could use e-mail lists to contact students. The distribution of participation during the survey period is represented in Figure 4 . In week 24 we started to send reminders to non-responders.

In the final questionnaire, we asked about e-learning affinity and intensity of computer use. There were no relevant associations between higher e-learning affinity or more intense computer use and faster submission of questionnaires ( $r=0.04$ and $r=0.002$, respectively).

\section{Mail-outs and response rates}



Figure 2. Details of the final study sample size and numbers of mail-outs versus response rates The whole circle represents the number of individuals who registered for participation in the survey $(n=10,993=100 \%) .1,1 \%$ registered twice and $3 \%$ of the e-mail addresses were incorrect. $13,3 \%$ of registered students did not respond to our email; $82,6 \%(n=9079)$ of all those who registered and were contacted by e-mail completed and returned the questionnaire.

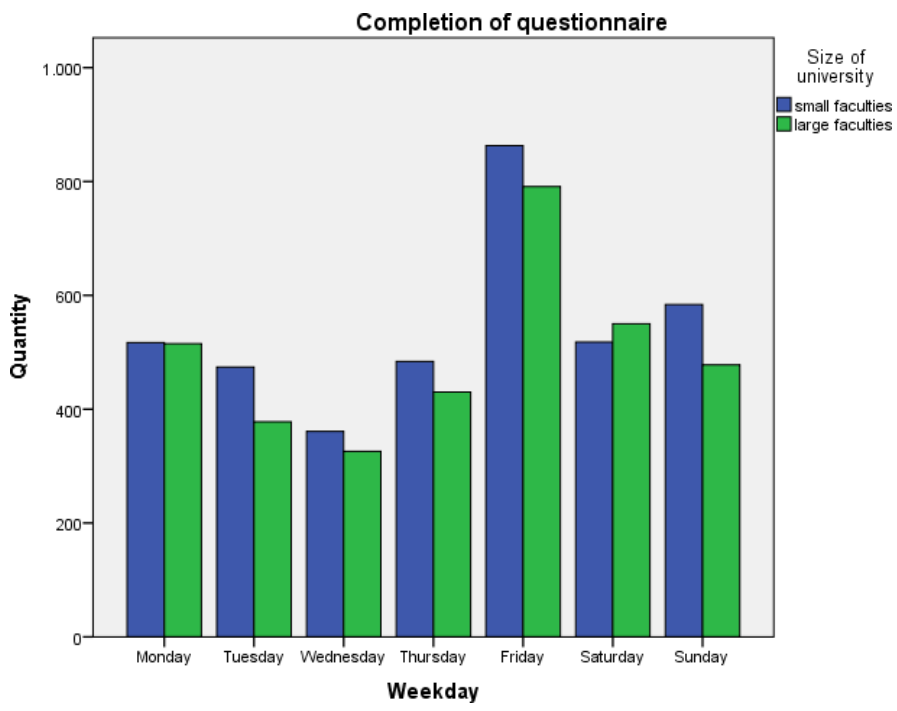

Figure 3. Day of completion of questionnaire in relation to faculty size

The graph presents the relationship between weekday and the completion of questionnaire according to the size of university. There was no significant difference in questionnaire submission time between students from large and small faculties.

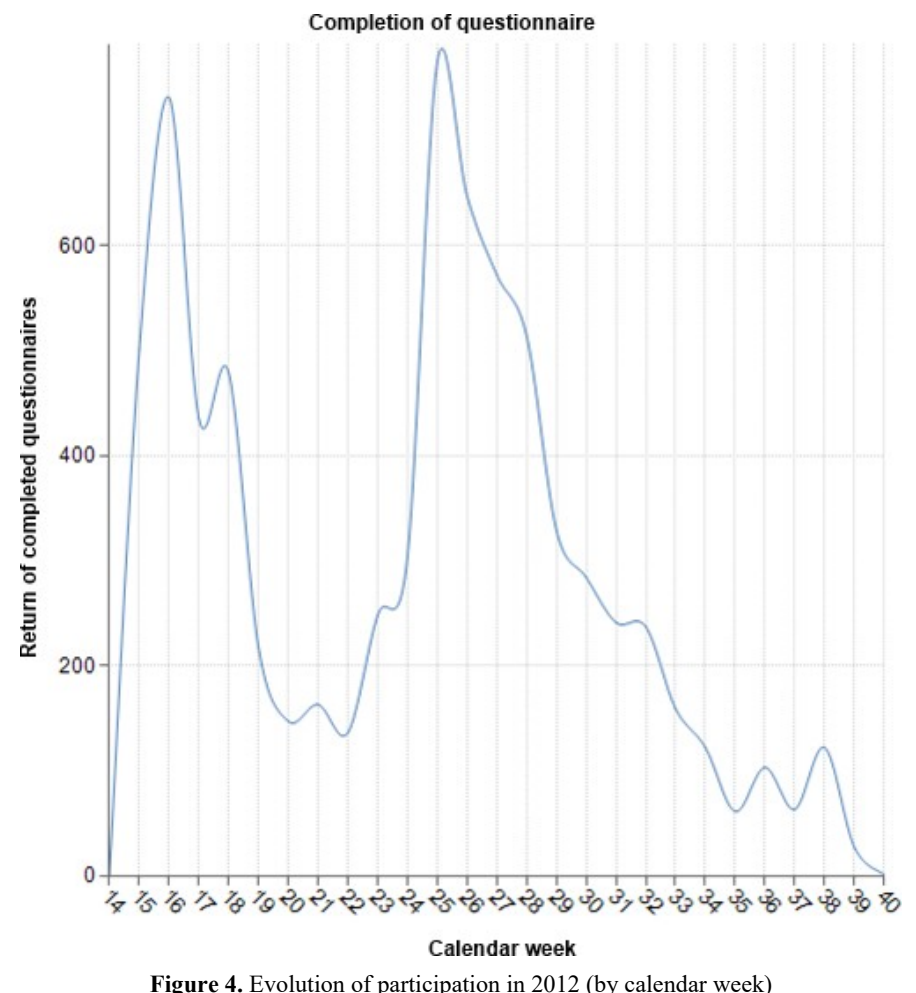

The graph presents return of completed questionnaires through the survey period. There are several peaks, which followed periods when new universities were included. The first and the second peak reflect the impact of inclusion of a new university with a mailing system to contact students. The second peak additionally represents the effect of reminding all those participants who had registered for participation but did not return the completed questionnaire; we started to send reminders to non-responders on Friday of the 24th calendar week.

Women took on average slightly longer than men in completing the questionnaire after registration (7.2 days versus 6.7 days). The difference was not significant $(\mathrm{p}=0.62)$. Regarding days of the week on which questionnaires were completed, we found a highly significant association $(\mathrm{p}<0.001)$. Most questionnaires were completed on Fridays, while the completion rate was lowest for Tuesdays through Thursdays.

\section{Discussion}

For our survey, we used an internet-based questionnaire because more students can be reached through the World Wide Web and because it facilitates analysis and processing and reduces costs compared to using paper-based questionnaires [32]. Disadvantages of an Internet survey include that affinity to new media may vary among groups of students or that the online link may be shared with individuals not supposed to be in the cohort [28]. Knowing about the advantages and disadvantages of an online-based survey [33-35], we opted for an internet-based approach, which turned out to be feasible and elicited responses from a large number of students, who are very familiar with the World Wide Web [28]. We did not identify important associations of gender, use of computers, e-learning affinity, or faculty size and the time it took to complete the questionnaire. These results suggest that we were able to address a wide range of medical students and not only those with an affinity for computer use [28]. Furthermore, the response rate shows that the level of computer and web use is high enough for an online-based study [27,30].

The results of our pilot studies indicate that the questionnaire measures what we intended and that we chose an adequate procedure. 
The finding of our pilot phase that work-life balance is becoming more important for medical students with increasing practical experience is in agreement with the results of earlier studies [22,36-39]. As expected from the results of earlier studies, our preliminary data show that medical students show little interest in working in research. However, reasons for the lack of interest cannot be derived from our preliminary analysis [40]. These preliminary results already indicate that analysis of the final survey will provide interesting data regarding how medical studies and clinical education can be improved in the future. During the test phase, we noted different strengths and weaknesses of the pilot survey. These concerned two aspects - first, the structure of the questionnaire and the back office and second, the design of the survey.

i. Students were asked to feedback difficulties they encountered while completing the questionnaire. A frequent criticism was that EvaSys education allowed marking of only one of five possible answers. This was changed in the final questionnaire. Concerning the structure of the questionnaire, we received useful feedback concerning missing answering options.

ii. During the test phase, questionnaires were completed by students who were directly approached by the investigators. Therefore, the preliminary results are not representative. However, in conjunction with data published in earlier studies, we expect statistically significant data from our revised questionnaire.

The questions concerning job satisfaction in the second part were inspired by the two-factor theory of Frederick Herzberger [41], who assumes that there are always two factors that have an impact on satisfaction. Firstly, dissatisfiers, which are factors from the job context that may fight dissatisfaction but are not able to produce satisfaction, and secondly satisfiers, which are factors from the job context that can make you satisfied. Employers knowing these factors can eliminate or minimize dissatisfiers while maintaining or enhancing satisfiers to attract jobseekers. Our results show that our extensive questionnaire, with more than 150 questions per participant, was on average completed and returned within one weekday. A total of $82.6 \%$ of all questionnaires mailed out were completed and returned. Several investigators have shown that the response rate decreases with length of a questionnaire $[42,28,43]$. The fact that we could motivate many medical students appears to be attributable to the keen interest in the sociopolitical topics of the questionnaire. The pilot phases helped us in improving our questionnaire in that we could eliminate minor errors such as poor wording, misleading questions, or ordering of questions $[31,44]$. From the test phase, we also learned that online completion of the questionnaire was too slow. We therefore upgraded the server web cache and the screen-by-screen designs became faster. Furthermore, it is likely that generation $\mathrm{Y}$ medical students are more used to online questionnaires than students participating in earlier surveys $[31,32,28,30,42]$.

Most questionnaires were completed and returned on Fridays. This may be due to the fact that we mailed up to 4 reminders per participant, starting in week 24, on Fridays and that responders tended to return questionnaires within a few days. The return rate was also slightly higher on Saturdays and Sundays, while Tuesdays through Thursdays had the lowest response rate. These results confirm that it is efficient to send reminders on Fridays just before the weekend. [26,29] Furthermore, there was a steep increase in questionnaire return after starting the email reminder protocol, so we can recommend the use of this tool to other groups doing a similar survey $[29,28,26]$. Overall, the response rate was lower at the beginning of the week. The response rates from different universities suggest that support of our survey by the universities was an important factor. [26,45,46] Eliciting the support of universities for our project was not easy. Once our survey was officially supported by a university, the number of contacts and participants rose significantly. [45] The relative number of participants differed considerably among universities. During the field time of the online questionnaire it turned out that the uses of mailing lists in single universities were significantly different.

\section{Limitation}

The authors have no data on how many of all medical students were aware of the project. So we don't have Information according to the factual consumption of the population. Furthermore, as support and advertising for our survey varied from university to university, not all medical students and young doctors had the same chance of knowing about this survey and participating. Therefore, the survey is not representative of all German medical students and young doctors from a statistical point of view. Nevertheless, basic characteristics of the sample such as sex distribution, age structure, or the proportion of student parents are representative of the population of all medical students $[6,47,48]$. For this reason and because of the homogeneity of central results of our survey and because of the high structural convergence with other surveys, there appears to be no evidence suggesting that our survey misrepresents the attitudes, evaluations, and expectations of future physicians in Germany. Rather, we assume that the results are typical of the motivations and dispositions of our target group.

\section{Conclusion}

A large sample of over 9000 responders out of a population of about 90,000 gives a good picture of students and young doctors in Germany. The participants answered within one day. Testing our questionnaire in different pilot versions helped us improve on it. The results of our final survey are expected to provide many valuable insights into the expectations of future generations of physicians and their criticism of the current situation. We will be able to answer specific questions regarding differences between women and men seeking a medical career or regional differences in the availability of medical care in Germany. The data can help us in addressing shortages and improving medical care in rural areas and provide a basis for political decision making.

\section{Acknowledgements}

The authors would like to thank the University of Greifswald for allowing us to use EvaSys education and the DGOU for providing $10000 €$ for this study. Special thanks are due to the AG Lehre of the DGOU for their support in developing the questionnaire.

\section{References}

1. Gorman DF, Brooks PM (2009) On solutions to the shortage of doctors in Australia and New Zealand. Med J Aust 190: 152-156. [Crossref]

2. Hooker RS, MacDonald K, Patterson R (2003) Physician assistants in the Canadian Forces. Mil Med 168: 948-950. [Crossref]

3. Adler G, v d Knesebeck JH (2011) [Shortage and need of physicians in Germany? Questions addressed to health services research]. Bundesgesundheitsblatt Gesundheitsforschung Gesundheitsschutz 54: 228-237. [Crossref]

4. Bennett KL, Phillips JP (2010) Finding, recruiting, and sustaining the future primary care physician workforce: a new theoretical model of specialty choice process. Acad Med 85: S81-88.

5. Dorsey ER, Jarjoura D, Rutecki GW (2005) The influence of controllable lifestyle and sex on the specialty choices of graduating U.S. medical students, 1996-2003. Acad Med 80: 791-796. [Crossref] 
6. Kopetsch T (2010) Dem deutschen Gesundheitswesen gehen die Ärzte aus! - Studie zur Altersstruktur-und Arztzahlentwicklung. Berlin: Bundesärztekammer und Kassenärztliche Bundesvereinigung.

7. Newton DA, Grayson MS, Thompson LF (2005) The variable influence of lifestyle and income on medical students' career specialty choices: data from two U.S. medical schools, 1998-2004. Acad Med 80: 809-814.

8. Gibis B, Heinz A, Jacob R, Muller CH (2012) The career expectations of medical students: findings of a nationwide survey in Germany. Dtsch Arztebl Int 109: 327-332.

9. Weiner JP1 (2007) Expanding the US medical workforce: global perspectives and parallels. BMJ 335: 236-238. [Crossref]

10. Freed GL, Stockman JA (2009) Oversimplifying primary care supply and shortages. JAMA 301: 1920-1922. [Crossref]

11. Dini L, Sarganas G, Heintze C, Braun V (2012) Home visit delegation in primary care: acceptability to general practitioners in the state of Mecklenburg-Western Pomerania, Germany. Dtsch Arztebl Int 109: 795-801. [Crossref]

12. Schmidt CE, Möller J, Schmidt K, Gerbershagen MU, Wappler F, et al. (2011) [Generation Y: recruitment, retention and development]. Anaesthesist 60: 517-524. [Crossref]

13. Osenberg D, Huenges B, Klock M, Huenges J, Weismann N, et al. (2010) Wer wird den noch Chirurg? Zukunftspläne der Nachwuchsmediziner an deutschen Universitäten. Chirurg 6: 308-315.

14. Parment A (2009) Die Generation Y - Mitarbeiter der Zukunft Herausforderung und Erfolgsfaktor für das Pesonalmanagement. Wiesbaden: GWV Fachverlage GmbH p. 183.

15. Hauer KE, Durning SJ, Kernan WN, Fagan MJ, Mintz M, et al. (2008) Factors associated with medical students' career choices regarding internal medicine. JAMA 300: $1154-1164$

16. Lee M, Wimmers PF (2011) Clinical competence understood through the construct validity of three clerkship assessments. Med Educ 45: 849-857.

17. Birch DW, Mavis B (2006) A needs assessment study of undergraduate surgical education. Can J Surg 49: 335-340.

18. Gormley GJ, Collins K, Boohan M, Bickle IC, Stevenson M (2009) Is there a place for e- learning in clinical skills? A survey of undergraduate medical students' experiences and attitudes. Med Teach 31: e6-e12.

19. Moule P, Albarran JW, Bessant E, Brownfield C, Pollock J (2008) A non-randomized comparison of e-learning and classroom delivery of basic life support with automated external defibrillator use: a pilot study. Int J Nurs Pract 14: 427-434.

20. Newton DA, Grayson MS (2003) Trends in career choice by US medical schoo graduates. JAMA 290: 1179-1182. [Crossref]

21. Tolhurst HM, Stewart SM (2004) Balancing work, family and other lifestyle aspects: a qualitative study of Australian medical students' attitudes. Med J Aust 181: 361-364.

22. Heinz A, Jacob R (2012) Medical students and their career choices. Preferred specialty, where and how to work. Bundesgesundheitsblatt Gesundheitsforschung Gesundheitsschutz 55: 245-253.

23. Hudson JN, Weston KM, Farmer EA (2012) Medical students on long-term regional and rural placements: what is the financial cost to supervisors? Rural Remote Health 12: 1951. [Crossref]

24. Froehlich S, Obertacke U, Ruesseler M, Schwanitz P, Roth A, et al. (2011) An educational skills programme for undergraduate training in orthopaedic and trauma surgery. Z Orthop Unfall 149: 568-574.

25. Stagg P, Greenhill J, Worley PS (2009) A new model to understand the career choice and practice location decisions of medical graduates. Rural Remote Health 9: 1245. [Crossref]
26. Balajti I, Daragó L, Ádány R, Kósa K (2010) College Students' Response Rate to an Incentivized Combination of Postal and Web-Based Health Survey. Eval Health Prof. 33: 164-176. [Crossref]

27. Chretien KC, Greysen SR, Chretien J-P, Kind T (2009) Online posting of unprofessional content by medical students. JAMA 302: 1309-1315. [Crossref]

28. Fan W, Yan Z (2010) Factors affecting response rates of the web survey: A systematic review. Computers in Human Behavior 26: 132-139.

29. Porter SR, Whitcomb ME (2005) Non-response in student surveys: The role of demographics, engagement and personality. Research in higher education 46: 127- 152.

30. Garner J, O'Sullivan H (2010) Facebook and the professional behaviours of undergraduate medical students. Clin Teach 7: 112-115. [Crossref]

31. Couper MP, Conrad FG, Tourangeau R (2007) Visual context effects in web surveys Public Opinion Quarterly 71: 623-634.

32. Diment K, Garrett-Jones S (2007) How demographic characteristics affect mode preference in a postal/web mixed-mode survey of Australian researchers. Social Science Computer Review 25: 510-517.

33. Groves RM, Fowler JFJ, Couper MP, Lepkowski JM, Singer E, et al. (2004) Survey Methodology. Hoboken, New Jersey: John Wiley \& Sons P. 470.

34. Faulbaum F, Prüfer P, Rexroth M (2009) Was ist eine gute Frage? - Die systematische Evaluation der Fragenqualität. Wiesbaden: VS Verlag für Sozialwissenschaften p. 264

35. Porst R (2008) Fragebogen: Ein Arbeitsbuch.Wiesbaden: VS Verlag für Sozialwissenschaften p. 195.

36. Brosius F (2011) SPSS 19 Heidelberg: HJR Verlag p. 1050.

37. van den Bussche H, Quantz S (2008) Berufs(nicht)einstieg bei Ärzten und Ärztinnen: Wo liegt das Problem? In: Brähler E, Alfermann D, Stiller J, editors. Karriereentwicklun und berufliche Belastungen im Arztberuf. Göttingen: Vandenhoeck \& Ruprech pp. 117-128

38. Schmidt K, Meyer JE, Liebeneiner J, Schmidt CE, Hüttenbrink KB (2012) The shortage of qualified staff in Germany: a survey on head physicians' expectations of young doctors. HNO 60: 102-108. [Crossref]

39. Zupanic M, Hofmann M, Osenberg D, Gardeik K, Jansen P, et al. (2011) The aimed or feared professional future of medical students at the Univesity of Witten/ Herdecke. GMS Z Med Ausbild 28: Doc25. [Crossref]

40. Pieper C, Elkeles T (2012) Zukunftspläne von Greifswalder Medizinstudierenden; Ergebnisse einer Befragung im Kontext der Sicherstellung der medizinischen Versorgung in Mecklenburg-Vorpommern. ÄRZTEBLATT MECKLENBURGVORPOMMERN 22: 369 -373.

41. Mayrhofer W (2002) Motivation und Arbeitsverhalten. Personalmanagement, Führung, Organisation. Wien: Kasper, H, Mayrhofer pp 260-265.

42. Sheehan KB (2001) E-mail survey response rates: A review. Journal of Computer Mediated Communication. Journal of Computer Mediated Communication.

43. Walston JT, Lissitz RW, Rudner LM (2006) The influence of Web-based questionnaire presentation variations on survey cooperation and perceptions of survey quality. Journal of Official Statistics 22: 271-291.

44. Crawford SD, McCabe SE, Pope D (2005) Applying Web-based survey design standards. Journal of Prevention and Intervention in the Community 29: 43-66.

45. Fox G, Schwartz A, Hart KM (2006) Work-family balance and academic advancement in medical schools. Acad Psychiatry 30: 227-234. [Crossref]

46. Manfreda KL, Bosnjak M, Berzelak J, Haas I, Vehovar V (2008) Web surveys versus other survey modes. Int Jou of Market Research 50: 79-104.

47. Spinner G (2004) Gutachten zum Ausstieg aus der kurativen ärztlichen Berufstätigkeit in Deutschland. RambØ1l Management.

48. Gibis B, Heinz A, Jacob R, Müller CH (2012) The career expectations of medical students: findings of a nationwide survey in Germany. Dtsch Arztebl Int 109: 327-332. [Crossref]

Copyright: (C2018 Kasch R. This is an open-access article distributed under the terms of the Creative Commons Attribution License, which permits unrestricted use, distribution, and reproduction in any medium, provided the original author and source are credited. 